\title{
Outcomes of surgery for functional cardiac paragangliomas: A single-center experience of 17 patients
}

Xin Pei Liu, MD, Qi Miao, MD, Xing Rong Liu, MD, Chao Ji Zhang, MD, Guo Tao Ma, MD, and Jian Zhou Liu, MD

\section{ABSTRACT}

Objective: Cardiac paragangliomas are rare neuroendocrine tumors. Early surgical treatment improves clinical symptoms and prolongs survival. We review our experience in 17 patients who underwent surgical resection for functional cardiac paraganglioma.

Methods: Seventeen patients underwent surgery for functional cardiac paraganglioma from 2004 to 2017 were identified. Clinical data and long-term outcomes were extracted and analyzed.

Results: All 17 patients with cardiac paraganglioma (11 males) with a median age of 35 years (range, 11 to 51 years) were hormonally functional and underwent operations. A 24-hour urine catecholamine assay documented elevation of norepinephrine, epinephrine, and dopamine. Tumors were determined with octreotide scintiscan in all 17 patients and metaiodoben-zylguanidine scintigraphy in 10 of 15 patients. Tumor sites were right atrioventricular groove in 4 patients, between the main arteries in 10 patients, and interatrial groove in 4 patients. All patients underwent complete resection. Concomitant surgeries were: structural reconstruction in 16 patients $(94 \%)$ and coronary artery bypass graft in 8 patients $(47 \%)$. One patient had a history of incomplete resection of an intra-atrial tumor. One patient died postoperatively. Operative mortality is $5.8 \%$. During follow-up (mean, 6.5 years; range, 1.5 to 14.2 years), 16 patients are alive in functional class I or II. Two patients developed tumor recurrence and 14 remained symptom-free with normal urinary catecholamines.

Conclusions: With a multidisciplinary treatment, early diagnosis, complete resection for the tumor along with complex reconstruction is achievable for most patients, and it offers promising long-term survival. ( $\mathrm{J}$ Thorac Cardiovasc Surg 2019;157:1556-64)

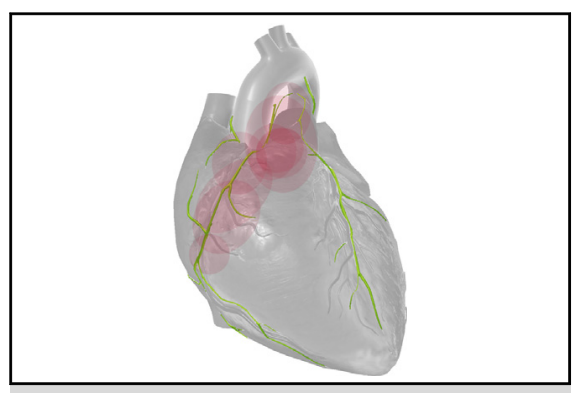

Distribution of 18 functional cardiac paragangliomas (red discs) on the heart.

\section{Central Message}

Complete surgical resection and reconstruction is possible for most functional cardiac paraganglioma patients. Satisfactory postoperative survival and long-term outcome are expectable.

\section{Perspective}

As a single institutional study of functional cardiac paraganglioma, we review our singlecenter experience of surgical treatment of 17 patients and demonstrate its common complications and outcomes. With high postoperative survival and good long-term outcome, we recommend to considering complete tumor resection and reconstruction as the first choice.

See Commentary on page 1565 .
Cardiac paraganglioma is defined as a specific neuroendocrine tumor arising from heart. Not all paragangliomas can secrete catecholamine. ${ }^{1}$ Functional cardiac paraganglioma was defined when the measured catecholamine or metanephrine concentration was greater than the reference

From the Department of Cardiac Surgery, Peking Union Medical College Hospital, Beijing, China.

Supported by the National Key Research and Development Program of China Grant No. 2016YFC0901502.

Received for publication June 2, 2018; revisions received Aug 28, 2018; accepted for publication Sept 2, 2018; available ahead of print Nov 3, 2018.

Address for reprints: Qi Miao, MD, Department of Cardiac Surgery, Peking Union Medical College Hospital, 1 Shuaifuyuan, Wangfujing St, Dongcheng District, Beijing, China 100730 (E-mail: miaoqipumc@ hotmail.com).

$0022-5223 / \$ 36.00$

Copyright $($ c 2018 by The American Association for Thoracic Surgery

https://doi.org/10.1016/j.jtcvs.2018.09.013 range. ${ }^{2}$ The diagnosis is difficult and often delayed. Surgery for functional cardiac paraganglioma is more challenging because of vascular supply from coronary arteries and close anatomic proximity to the heart and main vessels. ${ }^{3}$ Between April 2004 and December 2017, 17 symptomatic patients had a diagnosis or functional cardiac paraganglioma and underwent surgical resection, several has been reported previously. ${ }^{4,5}$ We now review these cases, including clinical

Scanning this $\mathrm{QR}$ code will take you to the article title page to access supplementary information.

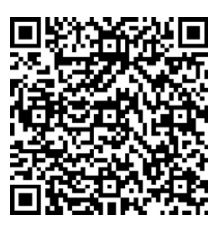



Abbreviations and Acronyms
Ao = ascending aorta
$\mathrm{AVG}=$ atrioventricular groove
$\mathrm{CPB}=$ cardiopulmonary bypass
$\mathrm{ECMO}=$ extracorporeal membrane oxygenator
IABP $=$ intra-aortic balloon pump
IAG $=$ interatrial groove
ICU = intensive care unit
MIBG = metaiodoben-zylguanidine scintigraphy
MPA = main pulmonary artery
OCT $=$ octreotide scintiscan

presentation, diagnosis, surgical management, and outcome.

\section{MATERIALS AND METHODS}

Approval for retrospective review was obtained from our institutional review board. Seventeen patients underwent operations for functional cardiac paragangliomas at the department of cardiac surgery of Peking Union Medical College Hospital between 2004 and 2017 were identified. Clinical data including demographic information, clinical manifestations, results of assays and radiographies, perioperative information, and follow-up data, including postoperative survival and current catecholamine level, were extracted from all available medical records. Preoperative medical therapy using $\alpha$-receptor blockers, $\beta$-receptor blockers, and calcium channel blockers was recorded. Intraoperatively, size and location of the tumor, procedure, duration of surgery, intraoperative hemodynamic information, postoperative inotropic agents, vasopressors, and mechanical support with an intra-aortic balloon pump (IABP), and extracorporeal membrane oxygenator (ECMO) were also recorded. Length of intensive care unit (ICU) stay, follow-up time, and current catecholamine level of all survival patients are also collected.

\section{RESULTS \\ Preoperative Characters}

Average age at admission was 35 years (range, 11 to 51 years), 11 of 17 patients $(65 \%)$ were male. 3 patients $(18 \%)$ were confirmed to have a family history of paraganglioma. At admission, 16 patients $(94 \%)$ complained paroxysmal hypertension, 11 patients $(65 \%)$ complained palpation, 9 patients $(53 \%)$ complained of headache, and 7 patients $(41 \%)$ complained of perspiration. Two patients $(12 \%)$ also complained of chest pain. Length of symptom ranged from 2 to 25 years (mean, 9.5 years). Under a $24-$ hour urine catecholamine assay, urinary norepinephrine was elevated in 15 patients $(88 \%)$, epinephrine was elevated in 5 patients $(29 \%)$, and dopamine was elevated in 8 patients $(47 \%$; Table 1$)$.

All patients were hormonally functional and were prepared for surgery using $\alpha$-receptor blockers, $\beta$-receptor blockers, and calcium channel blockers for 10 to 14 days following the guidelines for paraganglioma. ${ }^{6}$

\section{Value of Different Imaging Methods}

Multiple imaging techniques were used to determine and locate the tumor. OCT (Figure 1) were adopted in all cases, all of which were positive. Among 15 patients who underwent

TABLE 1. Preoperative characteristics

\begin{tabular}{|c|c|c|c|c|c|c|c|}
\hline $\begin{array}{l}\text { Patient } \\
\text { number }\end{array}$ & Sex & Age (years) & $\begin{array}{l}\text { Family } \\
\text { history }\end{array}$ & Presentation & $\begin{array}{c}\text { Urinate } \\
\text { catecholamine }\end{array}$ & $\begin{array}{c}\text { Syndrome } \\
\text { length (years) }\end{array}$ & $\begin{array}{l}\text { Medical } \\
\text { prepare }\end{array}$ \\
\hline 1 & Male & 11 & None & Perspiration, palpation, HTN & NE, DoA & 9 & $\alpha, \beta$ \\
\hline 2 & Male & 34 & Yes & Palpation, chest pain, HTN & $\mathrm{NE}$ & 1 & $\alpha, \beta$ \\
\hline 3 & Male & 13 & None & Perspiration, HTN & NE, E, DoA & 5 & $\alpha, \beta$ \\
\hline 4 & Male & 19 & None & Perspiration, palpation, headache, HTN & NE, E, DoA & N/A & $\alpha$ \\
\hline 5 & Female & 23 & None & Perspiration, palpation, headache, HTN & NE, DoA & 4 & $\alpha$ \\
\hline 6 & Male & 48 & None & Perspiration, palpation, headache, HTN & $\mathrm{NE}, \mathrm{E}$ & 15 & $\alpha$ \\
\hline 7 & Female & 50 & None & Palpation, HTN & None & 10 & $\alpha$ \\
\hline 8 & Male & 50 & None & Palpation, headache, HTN & NE, DoA & 2 & $\alpha, \beta$ \\
\hline 9 & Male & 44 & Yes & Palpation, HTN & DoA & 20 & $\alpha$ \\
\hline 10 & Female & 35 & None & Perspiration, headache, HTN & NE, E, DoA & 3 & $\alpha$ \\
\hline 11 & Male & 51 & None & Perspiration, palpation, headache, HTN & $\mathrm{NE}$ & 16 & $\alpha$ \\
\hline 12 & Female & 21 & None & Palpation, headache, chest pain, HTN & $\mathrm{NE}$ & 2 & $\alpha, \beta$ \\
\hline 13 & Female & 48 & None & HTN & $\mathrm{NE}$ & 6 & $\alpha, \beta, \mathrm{CCB}$ \\
\hline 14 & Male & 17 & None & Headache, HTN & $\mathrm{NE}, \mathrm{E}$ & 13 & $\alpha, \beta$ \\
\hline 15 & Female & 48 & None & Perspiration, headache, HTN & NE, DoA & 25 & $\alpha$ \\
\hline 16 & Male & 37 & None & Perspiration, palpation, headache, HTN & $\mathrm{NE}$ & N/A & $\alpha$ \\
\hline 17 & Male & 45 & Yes & Palpation, headache & $\mathrm{NE}, \mathrm{E}$ & 12 & $\alpha, \beta, \mathrm{CCB}$ \\
\hline
\end{tabular}

$H T N$, Hypertension; $N E$, norepinephrine; $D o A$, dopamine; $\alpha, \alpha$-receptor blocker; $\beta, \beta$-receptor blocker; $E$, epinephrine; $C C B$, calcium channel blocker. 


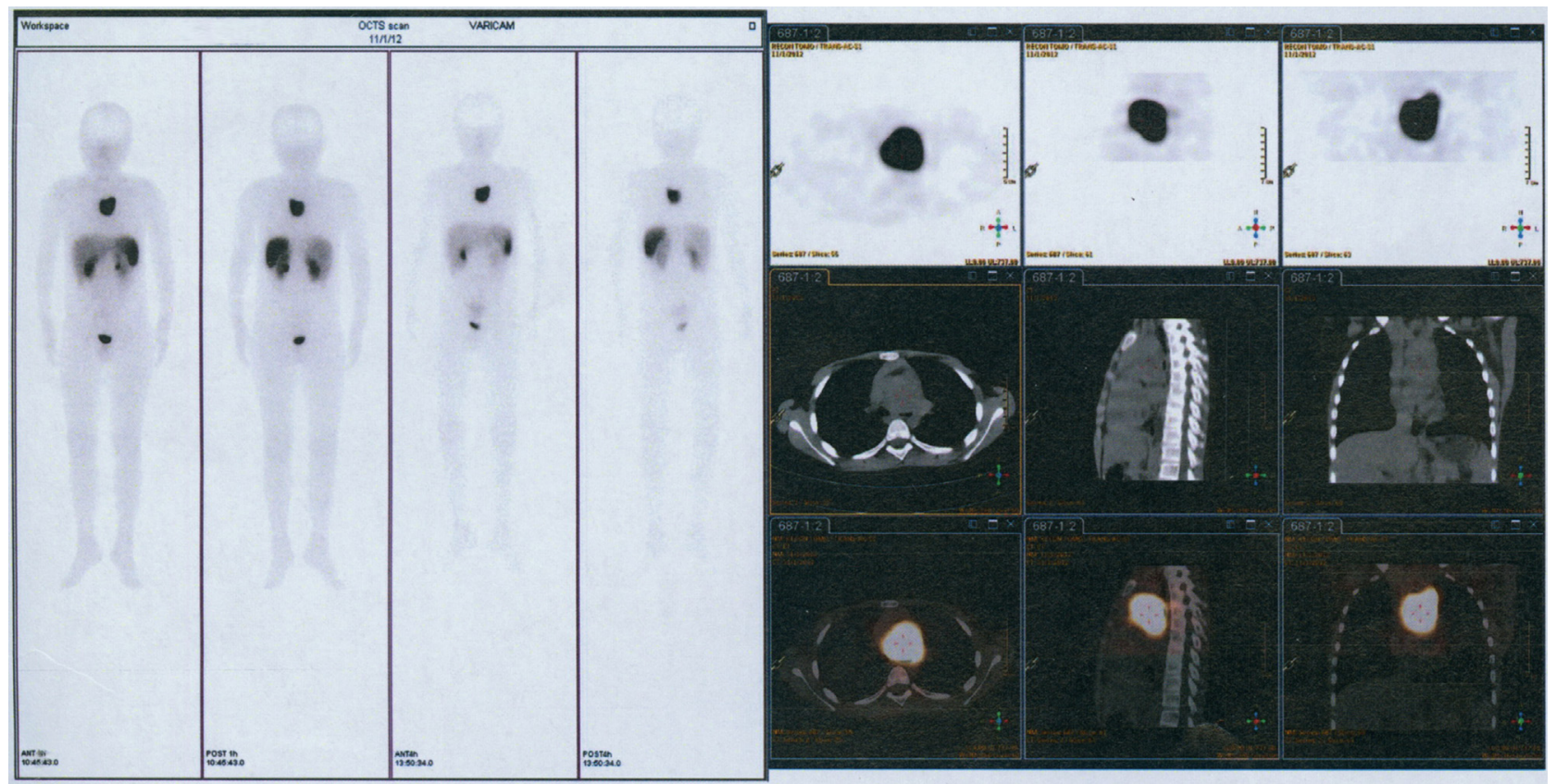

FIGURE 1. Otide scintiscan showed a focus of intense uptake on right side of the heart silhouette, indicating the location of the left atrium.

metaiodoben-zylguanidine scintigraphy (MIBG; Figure 2), 10 patients $(67 \%)$ had positive results. Tumors were located under multiple imaging tests (Figure 3). To elucidate the blood supply of the tumor, coronary arteriography was adopted in all cases (Video 1). Blood supply of all 18 tumors of 17 patients were from the coronary artery (Figure 4). Twelve tumors $(67 \%)$ were fed by the left coronary system, 11 tumors $(61 \%)$ were fed by right coronary system, and 5 tumors (28\%) had dual supply from left and right coronary circulation.

\section{Intraoperative Findings}

Among 18 tumors in 17 patients, 10 tumors (56\%) were located at the root of the ascending aorta (Ao) or the main pulmonary artery (MPA), 4 tumors $(22 \%)$ were located in the right atrioventricular groove (AVG), and 4 tumors $(22 \%)$ were located in the interatrial groove (IAG), respectively (Figure 5). The average size of tumors was $60 \times 48 \mathrm{~mm}$ (range, $30 \times 30 \mathrm{~mm}$ to $100 \times 80 \mathrm{~mm}$ ). Local invasion of the tumor was found intraoperatively in 8 patients $(47 \%)$. In the other 9 patients, tumors were found to have continued capsules. All patients underwent complete tumor resection under cardiopulmonary bypass (CPB). A variety of autologous, allogeneic and synthetic vascular grafts were used for concomitant reconstruction in 16 patients $(94 \%)$. Coronary artery bypass grafting was adopted in 8 patients $(47 \%)$. Average duration of CPB was 160 minutes (range, 42 to 328 minutes). Average duration of Ao cross-clamp was 105 minutes (range, 17 to
137 minutes). No heart transplantation was committed. Histologic and immunohistochemical examinations in all patients showed large polygonal cells with ample amphophilic cytoplasm and moderate nuclear pleomorphism. Chromogranin A immunohistochemistry showed positive staining in the tumor cells, representing cardiac paragangliomas (Table 2).

\section{Complications and Follow-up Information}

Perioperative hemorrhage was a common complication. In our 17 patients, the average amount of intraoperative blood transfusion was $4 \mathrm{U}$ (range, 0 to $8 \mathrm{U}$ ). Low cardiac output syndrome and vasoplegia were the next most common complications. Three patients $(17 \%)$ required ECMO support because of recalcitrant hypotension and subsequently presented tamponade that required emergent bedside thoracotomy and daily debridement. One patient died of bleeding complication 40 hours after ECMO implantation, and the other 2 patients recovered after 5 and 16 days of ECMO support, respectively. Among the 16 survival patients, average ICU stay was 6 days (range, 1 to 20 days). Average follow-up was 6.5 years (range, 1.3 to 14.2 years). Three patients (18\%) presented late endocrinal relapse at 3,10, 12 years, respectively, of whom 2 were diagnosed as recurrence of cardiac tumor, whereas the other was attributed to the residual of the adrenal pheochromocytoma. Fourteen of the patients $(82 \%)$ are free of symptoms and have normal 24-hour urinate catecholamine level currently (Table 3 ). 


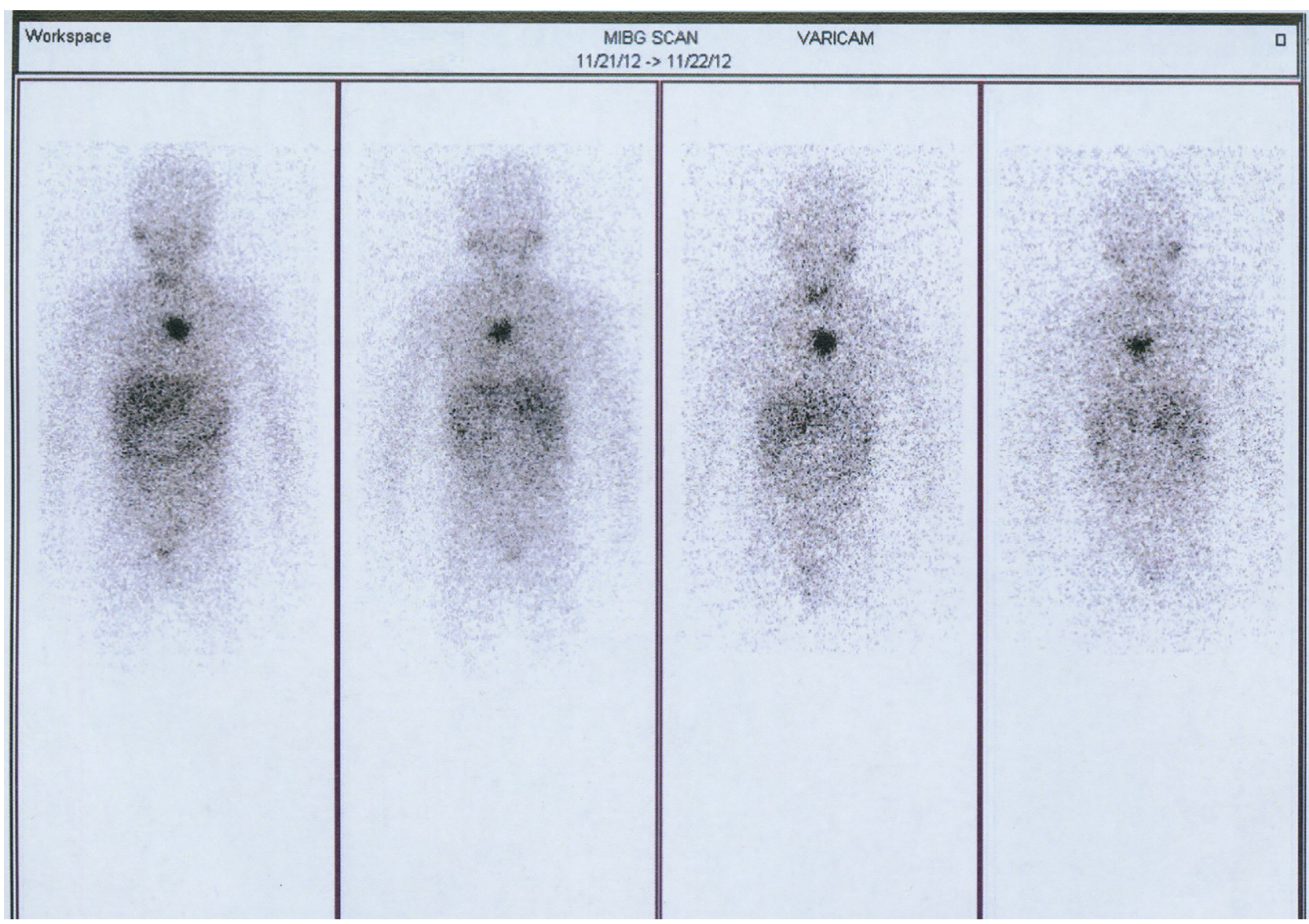

FIGURE 2. Metaiodoben-zylguanidine scintigraphy showed a focus of intense uptake on the right side of heart silhouette.

\section{DISCUSSION}

\section{Characters and Diagnosis}

Cardiac paraganglioma has an average age of onset of 39.7 years (range, 12 to 85 years) and a balanced M-F ratio. One third to half of paragangliomas were reported to be one of the symptoms of a genetic syndrome. ${ }^{8}$ A retrospective study including 14 patients of mediastinal paraganglioma found that $21 \%$ of patients had a family history, ${ }^{9}$ whereas $18 \%$ of patients in our study had a confirmed family history.

Headache, palpation, and perspiration are characteristic symptoms of functional paraganglioma because of high catecholamine secretion. ${ }^{9}$ Wang and colleagues ${ }^{7}$ also reported symptoms of chest pain in cardiac paraganglioma. Twelve percent of patients in our study complained of chest pain. However, in our series of patients, the average length of symptom before diagnosis is 9.5 years, indicating that the diagnosis of functional paraganglioma is difficult and often delayed, which is in accordance with the literature. ${ }^{2}$ Actually, the diagnosis can be improved with the help of urine catecholamine assays and multiple imaging techniques. Urine catecholamine levels are high in $31 \%$ of patients with paraganglioma, but in functional paragangliomas, norepinephrine elevates most frequently. ${ }^{10}$ In our study, all 18 cardiac paragangliomas were hormonally functional, which we considered the result of referral bias. The Mayo study reported no elevation of urinate epinephrine. ${ }^{9}$ In our study, functional cardiac paragangliomas could secrete all types of catecholamines, even 2 or 3 types at the same time. High norepinephrine level was detected most frequently. The value of MIBG has been emphasized since 1995, when Jeevanandam and colleagues ${ }^{11}$ reported its significance in the determination of cardiac paraganglioma. According to our data, MIBG seems not to be as sensitive as OCT $(67 \%$ vs $100 \%)$, although not statistically significant because of the poor sample size. The advantage of MIBG is its high specificity, and it should be significant for final qualitative diagnosis. Therefore, we consider urine catecholamine assay, combined with multiple imaging techniques, as sufficient measures for differentiation between functional cardiac paragangliomas and other primary cardiac tumors. Furthermore, experience with preoperative coronary angiography to detect tumor blood supply has 


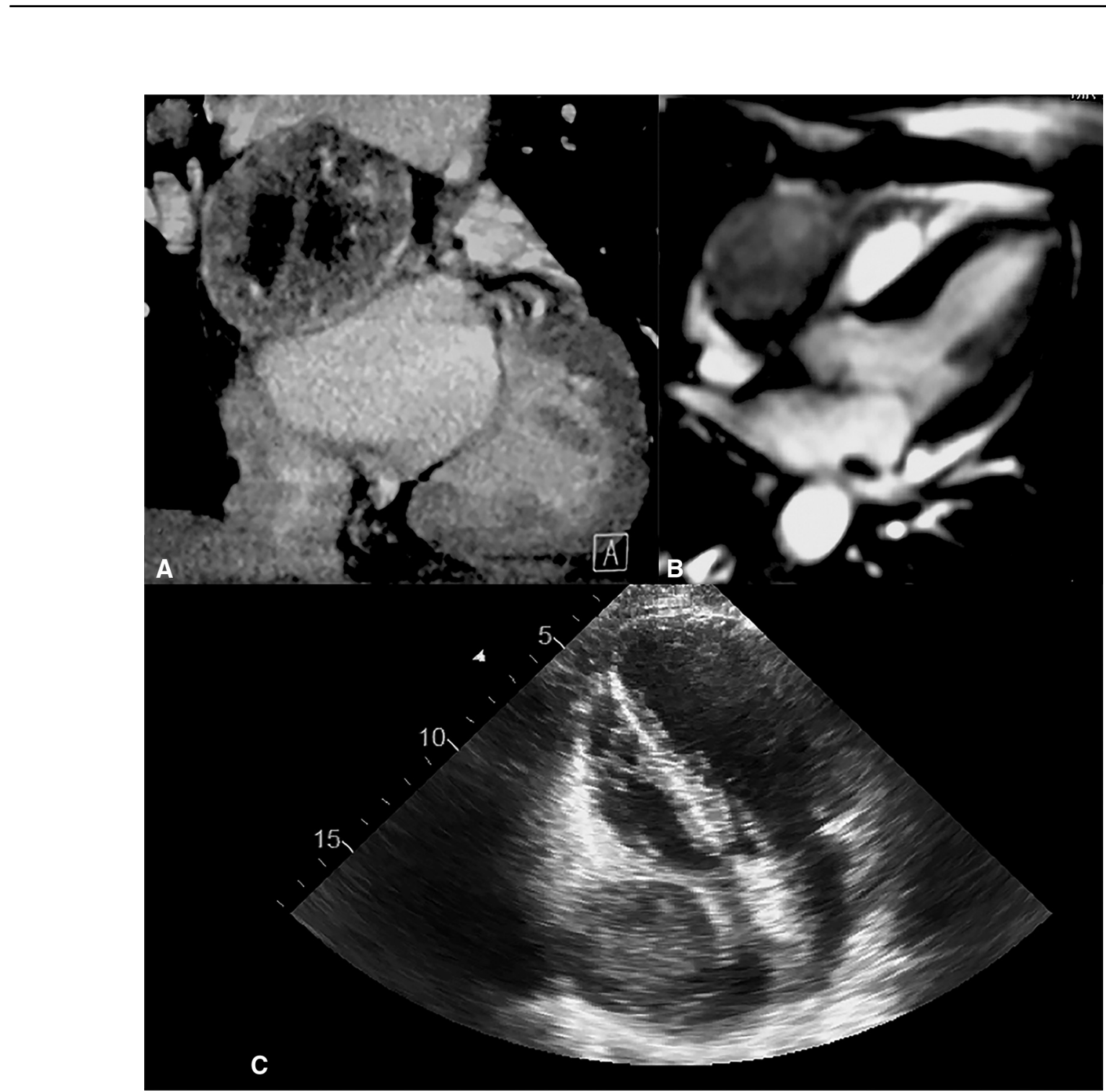

FIGURE 3. Tumors can be located under multiple imaging tests including (A) contrast-enhanced computed tomography, (B) magnetic resonance imaging, and (C) transthoracic echocardiography.

been reported in several studies. ${ }^{3}$ In our study, all 18 tumors were fed by the coronary artery, and nearly half of patients underwent $\mathrm{CABG}$, which made preoperative coronary angiography even more significant.

\section{Tumor Location}

Although fewer than 160 cases have been reported in the literature, a wide variety of the tumor sites could be found. According to the review by Wang and colleagues, ${ }^{7}$ cardiac paraganglioma mostly originated from the epicardium and the root of great vessels. In our study, most tumors were located near the root of Ao and MPA, whereas others were located in the right atrioventricular groove and interatrial groove, similar to the distribution of the cardiac plexus (Figure 5). It can be explained by the embryonic origin of paraganglioma. ${ }^{12}$

\section{Preoperative Medical Treatment}

Preoperative medical preparation for functional paraganglioma was recommended by the guidelines ${ }^{6}$ to prevent perioperative hemodynamic fluctuation. Several studies hold the opinion that preoperative medical treatment is not necessary for tumor resection, ${ }^{13,14}$ whereas no randomized controlled studies provide reliable evidence. Therefore, we continued the preoperative medical treatment for our patients, the same as the newest report from the Mayo Clinic. ${ }^{1}$ However, the specific regimen should be negotiated with endocrinologists.

\section{Malignancy of the Tumor}

The 2004 World Health Organization Classification of Tumors considered that the one and only criterion of malignancy of paraganglioma was metastasis. ${ }^{15}$ Diagnosis of 


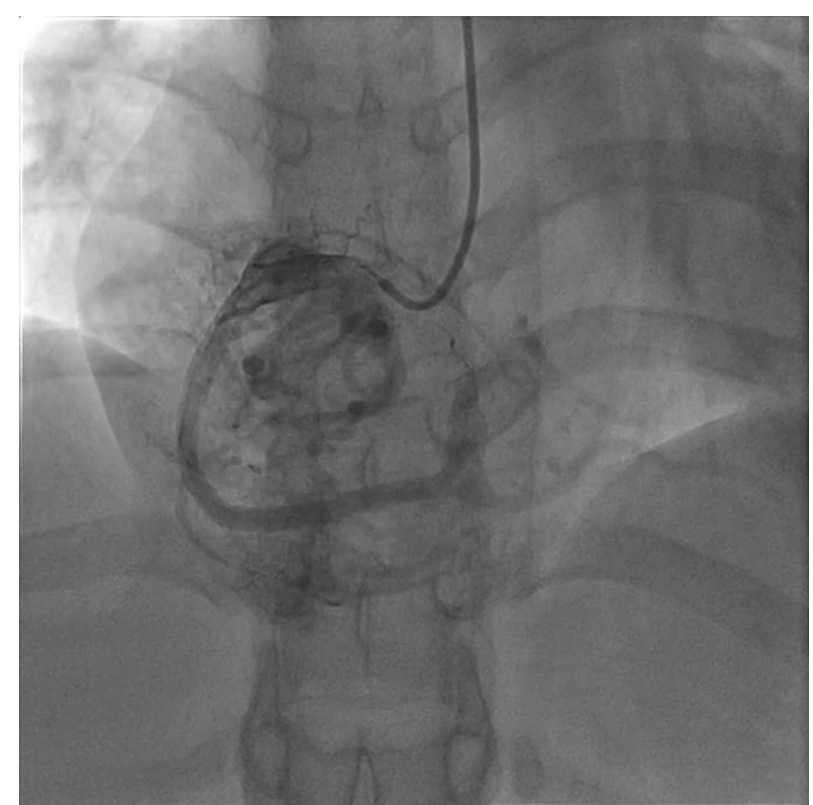

VIDEO 1. Preoperative coronary arteriography for patient 5 demonstrated a large oval-shaped tumor with rich blood supply from the right coronary artery and branches. Video available at: https://www.jtcvs.org/article/ S0022-5223(18)32512-1/fulltext.

malignant paraganglioma requires evidence of metastases at nonchromaffin sites distant from the primary tumor, such as the lymph nodes, bones, or liver. Unfortunately, we recorded no distant metastasis in our series of patients. Although we have found local invasion of the tumor in 8 patients, it does not predict malignancy potential according to the literature. ${ }^{16}$

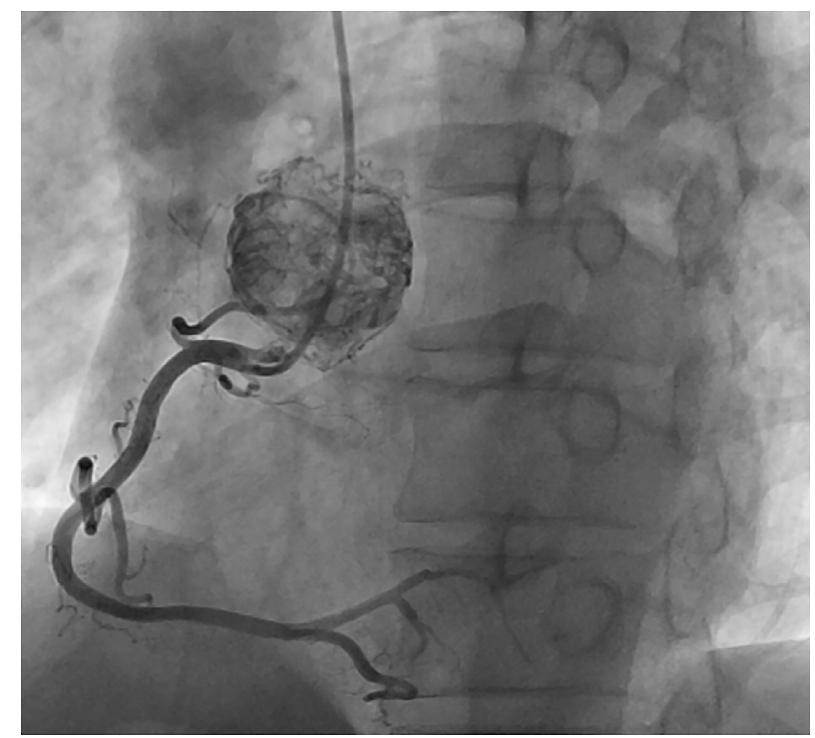

FIGURE 4. Coronary arteriography demonstrates a large oval-shaped tumor with a rich blood supply from the right coronary artery and branches.

\section{Surgical Procedure and Complications}

Inherent to this particular organ, surgery for functional cardiac paraganglioma usually poses more challenges including exposure, complete resection, and the need for complex reconstruction to preserve function. Because of the blood supply from coronary arteries, embolization is considered unwise. We routinely performed operations under CPB. Depending on tumor localization, extension to surrounding structure, and the presence of coronary artery involvement, surgical therapy includes complete tumor and involved cardiac tissue or vessels resection, and complex reconstruction using a variety of autologous, allogeneic, and synthetic vascular patches or grafts. Experience taught us that, because of the rich blood supply, resecting a few millimeters alongside the tumor edge caused less blood loss than clinging to the edge. Atrium injured can be easily patched using pericardium or other grafts. Usually, the feeding vessels from coronary arteries can be coagulated or clipped. When a main coronary artery was involved by tumor or incidentally injured, coronary artery bypass grafting was performed using either arterial or venous grafts (Video 2). Latest research stated that a 3-dimensional printing model would be helpful for familiarization with the anatomic interrelationship of tumor positioning within vascular structures. ${ }^{1}$ We noticed that most functional cardiac paragangliomas could be completely resected in their primary surgery. Redo surgery for tumor recurrence remains challenging, and we have only one experience with a patient with a history of previous incomplete resection of atrial septal tumor (patient 11). During the patient's second operation, we completely resected the residual paraganglioma involving interatrial groove and reconstructed both atria, coronary sinus and grafted the inferior vena cava (IVC).

An early study ${ }^{11}$ noted that intraoperative hemorrhage was the fiercest complication, and the authors recommended heart transplantation as a potential therapeutic strategy for paragangliomas invading the atrioventricular groove or directly invading the coronary artery. We agree that intraoperative hemorrhage remains a devastating complication of surgical resection. However, in our study, major bleeding is avoidable with meticulous reconstruction. Myocardial ischemia owing to coronary artery injury is usually reversible after a successful grafting. However, adrenergic receptor downregulation owing to preoperative catecholamine hypersecretion led to occurrence of recalcitrant hypotension where inotropic agents and vasopressors are required. ${ }^{1}$ Some patients developed vasoplegia; in this situation, ECMO support was absolutely needed. We had 3 patients using ECMO; 2 patients survived and 1 patient died of bleeding complication.

On some level, we absolutely agree that heart transplantation is an option for complete removal of cardiac tumors; 


\section{Adult: Cardiac Tumors}
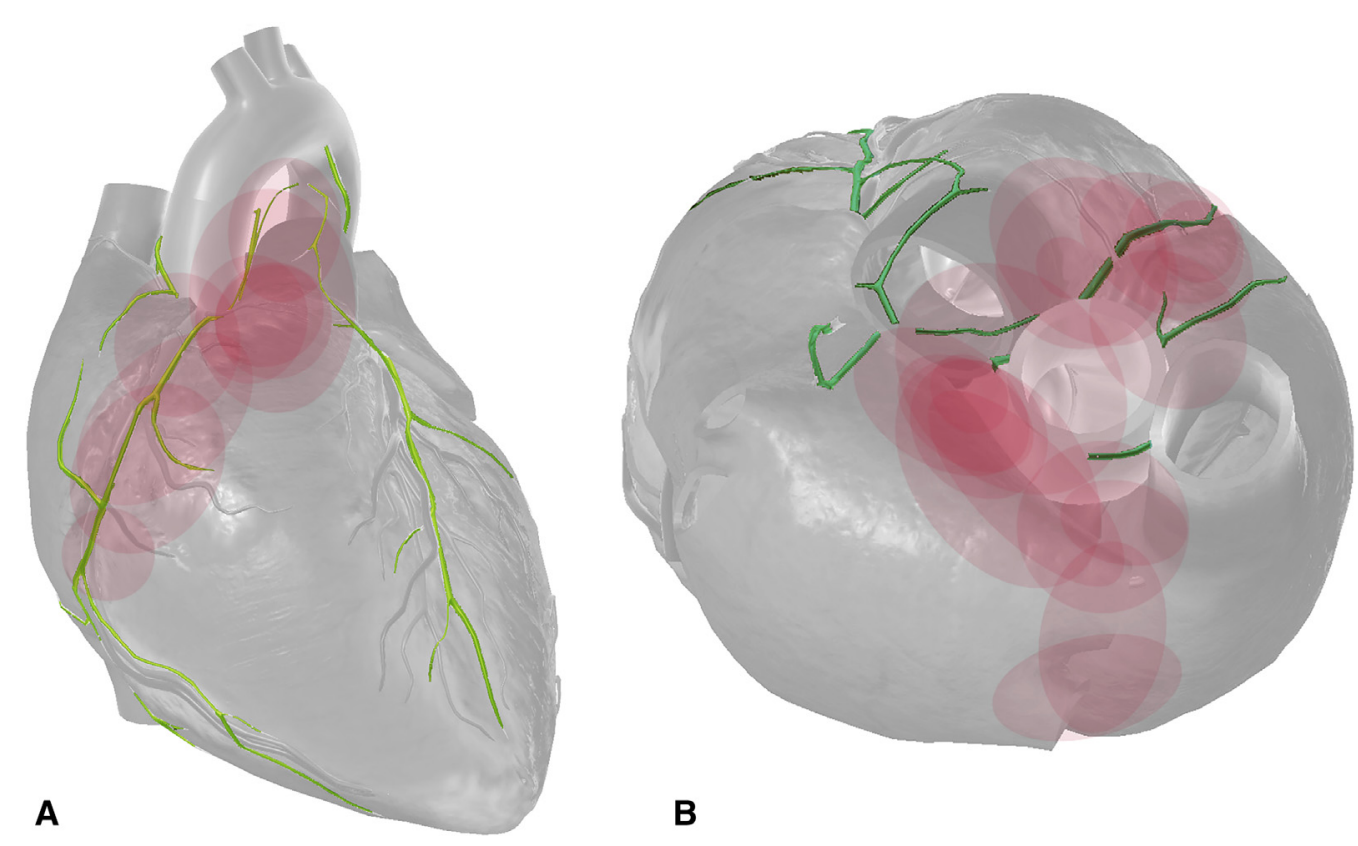

$\mathbf{B}$

FIGURE 5. Distribution of tumors (red discs) on the heart in (A) frontal and (B) axial view. Each disc has the similar size, shape, and position of a corresponding tumor. Deeper color means that tumors invaded this spot more frequently. Tumors were primarily located between the ascending aorta and the main pulmonary artery, in the interatrial groove, and in the atrioventricular groove, similar to the distribution of cardiac plexus (green line).

however, considering its unsatisfactory long-term results, ${ }^{17}$ we would not recommend transplantation as the first choice. We observed that operative mortality was comparable with previous reports. Although tumor recurrence occurred in 2 of our 16 surviving patients (patients 4 and 14), all survivors reported functional improvement, and $82 \%$ of patients had normal catecholamine levels during follow-up.

TABLE 2. Intraoperative findings

\begin{tabular}{|c|c|c|c|c|c|c|}
\hline $\begin{array}{l}\text { Patient } \\
\text { number }\end{array}$ & Tumor location & Tumor size (mm) & $\begin{array}{c}\text { Intraoperative } \\
\text { blood pressure } \\
(\mathrm{mm} \mathrm{Hg})^{*}\end{array}$ & $\begin{array}{c}\text { Local } \\
\text { invasion }\end{array}$ & Concomitant surgery & $\begin{array}{c}\mathrm{CPB} / \mathrm{Ao} \mathrm{X} \\
\text { clamp (minutes) }\end{array}$ \\
\hline 1 & Root of Ao & $74 \times 61$ & $160-50 / 70-30$ & No & Rec of Ao and LA & $90 / 57$ \\
\hline 2 & Root of Ao and MPA & $55 \times 34$ & $210-30 / 120-30$ & Yes & Rec of VS, MPA and RPA, CABG & $285 / 222$ \\
\hline 3 & Root of Ao and MPA & $100 \times 80$ & $180-90 / 80-60$ & No & Rec of RVOT and MPA, CABG & $170 / 193$ \\
\hline 4 & Right AVG & $67 \times 55$ & $170-50 / 100-30$ & Yes & Rec of RVOT and Ao, CABG & $93 / 50$ \\
\hline 5 & Right AVG & $75 \times 65$ & $140-60 / 90-30$ & No & Rec of RVOT, CABG & $171 / 92$ \\
\hline 6 & Root of MPA & $40 \times 30$ & $170-50 / 100-40$ & No & None & $42 / 17$ \\
\hline 7 & Root of Ao and MPA & $75 \times 64$ & $150-70 / 80-20$ & Yes & Rec of LA and VS, CABG & $265 / 199$ \\
\hline 8 & IAG & $40 \times 32$ & $140-40 / 100-20$ & No & Rec of LA, RA and RSPV, CABG & $139 / 105$ \\
\hline 9 & Root of Ao and MPA/Right AVG & $80 \times 55,60 \times 40$ & $150-80 / 80-40$ & Yes & Rec of Ao and MPA, CABG & $134 / 91$ \\
\hline 10 & IAG & $67 \times 55$ & $170-40 / 130-20$ & No & Rec of LA & $70 / 40$ \\
\hline 11 & IAG & $64 \times 60$ & $190-50 / 100-30$ & Yes & Rec of LA, RA, CS, IAS and IVC & $252 / 172$ \\
\hline 12 & Right AVG & $40 \times 30$ & $160-60 / 110-50$ & No & Rec of RA & $50 / 32$ \\
\hline 13 & Root of Ao and MPA & $50 \times 40$ & $160-50 / 90-30$ & Yes & Rec of Ao, CABG & $328 / 137$ \\
\hline 14 & Root of Ao and MPA & $59 \times 46$ & $140-40 / 60-30$ & Yes & Rec of Ao, MPA and RVOT & $143 / 90$ \\
\hline 15 & Root of Ao and MPA & $30 \times 30$ & $150-60 / 110-40$ & Yes & Rec of Ao and RPA & $127 / 82$ \\
\hline 16 & Root of Ao and MPA & $50 \times 47$ & $160-60 / 80-20$ & No & Rec of LA and RPA & $108 / 82$ \\
\hline 17 & IAG & $60 \times 45$ & $140-40 / 110-30$ & No & Rec of RA, IAS and IVC & $145 / 118$ \\
\hline
\end{tabular}

CBP, Cardiopulmonary bypass; Ao X clamp, aortic cross clamp; Ao, aorta; Rec, reconstruction; LA, left atrium; MPA, main pulmonary artery; VS, Valsalva sinus; RPA, right pulmonary artery; $C A B G$, coronary artery bypass grafting; $R V O T$, right ventricular outflow tract; $A V G$, atrioventricular groove; $I A G$, interatrial groove; $R S P V$, right superior pulmonary vein; $R A$, right atrium; $C S$, coronary sinus; IAS, intra-articular septum; $I V C$, inferior vena cava. *Presented as systolic pressure over diastolic pressure with ranges. 
TABLE 3. Complications and follow-up information

\begin{tabular}{|c|c|c|c|c|c|c|}
\hline $\begin{array}{l}\text { Patient } \\
\text { number }\end{array}$ & $\begin{array}{l}\text { Intraoperative } \\
\text { transfusion (U) }\end{array}$ & Perioperative complications & $\begin{array}{c}\text { ICU stay } \\
\text { (days) }\end{array}$ & $\begin{array}{l}\text { Postoperative } \\
\text { vasopressors }\end{array}$ & $\begin{array}{c}\text { Follow-up } \\
\text { time (years) }\end{array}$ & $\begin{array}{c}\text { Current } \\
\text { urinate CA }\end{array}$ \\
\hline 1 & 2 & IABP & 3 & $\mathrm{NE}$ & 5.2 & - \\
\hline 2 & 4 & LCOS, IABP, ECMO (16 d), hemorrhage (PT) & 20 & $\mathrm{NE}, \mathrm{E}$ & 3.5 & + \\
\hline 3 & 4 & None & 6 & NE, V & 2.3 & - \\
\hline 4 & 2 & None & 5 & NE & 12.5 & + \\
\hline 5 & 2 & LCOS, IABP, ECMO (5 d), hemorrhage (PT) & 16 & NE, E, DoA, V & 5.9 & - \\
\hline 6 & 0 & None & 1 & $\mathrm{NE}, \mathrm{E}$ & 2.4 & - \\
\hline 7 & 4 & IABP & 8 & NE, E, DoA & 2.9 & - \\
\hline 8 & 4 & None & 2 & NE, E, DoA & 8.9 & - \\
\hline 9 & 2 & None & 4 & NE, DoA & 10.9 & - \\
\hline 10 & 8 & None & 6 & NE, DoA & 13.7 & - \\
\hline 11 & 4 & None & 5 & $\mathrm{NE}, \mathrm{E}$ & 2.75 & - \\
\hline 12 & 8 & None & 7 & $\mathrm{NE}, \mathrm{E}$ & 2 & - \\
\hline 13 & 8 & LCOS, IABP, ECMO (1 d), hemorrhage (dead*) & 1 & NE, E, DoA, V & N/A & N/A \\
\hline 14 & 4 & None & 4 & NE, E, DoA & 14.2 & + \\
\hline 15 & 2 & None & 8 & $\mathrm{NE}, \mathrm{E}$ & 8.75 & - \\
\hline 16 & 0 & None & 2 & $\mathrm{NE}, \mathrm{E}$ & 7.3 & - \\
\hline 17 & 2 & None & 2 & $\mathrm{NE}, \mathrm{E}$ & 6.2 & - \\
\hline
\end{tabular}

ICU, Intensive care unit; $C A$, catecholamine; $L C O S$, Low Cardiac Output Syndrome; IABP, Intra-aortic Balloon Pumping; $E C M O$, Extracorporeal Membrane Oxygenation; $P T$, Pericardial Tamponade; $N E$, norepinephrine; $E$, epinephrine; $V$, vasopressin; $D o A$, dopamine. *This patient died postoperatively.

\section{CONCLUSIONS}

Functional cardiac paragangliomas are rare neuroendocrine tumors with catecholamine-secreting potential and close anatomic proximity to the heart and main vessels. Because of the neuroendocrine properties and risky

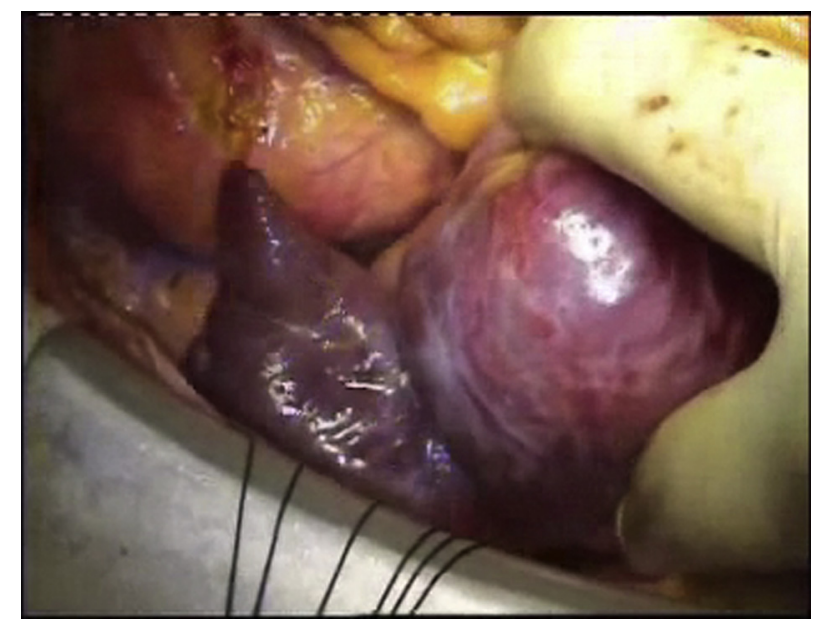

VIDEO 2. In patient 5 , tumor was found in the right atrioventricular groove and invaded into the myocardium. The right coronary artery (RCA) was involved by the tumor and injured during surgery. After complete resection of the tumor, ligation of the stumps of the RCA and venous grafting were performed. The large structural defect was reconstructed with pericardial patch to prevent bleeding. Video available at: https://www.jtcvs.org/article/S0022-5223(18)32512-1/fulltext. anatomic location, multidisciplinary treatment including the department of endocrinology, cardiac surgery, and ICU is necessary (Figure 6). Patients should undergo preoperative medical preparation under the guidance of endocrinologists. Despite the risk of intraoperative bleeding, complete resection for the tumor along with complex reconstruction is achievable. Postoperative low cardiac output syndrome and bleeding complication of ECMO are 2 main fatal complications. With the help of a professional heart team, good postoperative survival and long-term outcomes are expectable. However, because of the potential of recurrence, we recommend lifelong surveillance.

\section{Study Strengths and Limitations}

This retrospective study of 17 patients with functional cardiac paraganglioma is, to our knowledge, the largest single institutional study of functional cardiac paraganglioma to date. Although, the sample size of our study is limited, all of our patients received diagnoses, underwent operations, and received critical care from our multidisciplinary treatment team at Peking Union Medical College Hospital. None of our patients got a tumor extending to the left ventricle, where orthotopic transplantation may be a choice. ${ }^{11}$ We have not performed orthotopic transplantation for cardiac paraganglioma patients; therefore, we cannot assess the potential benefit. Besides, it is a retrospective study lacking a designed control group and rigorous contrast analysis, we can only compare our results with 
The PUMC Experience for Functional Cardiac Paraganglioma

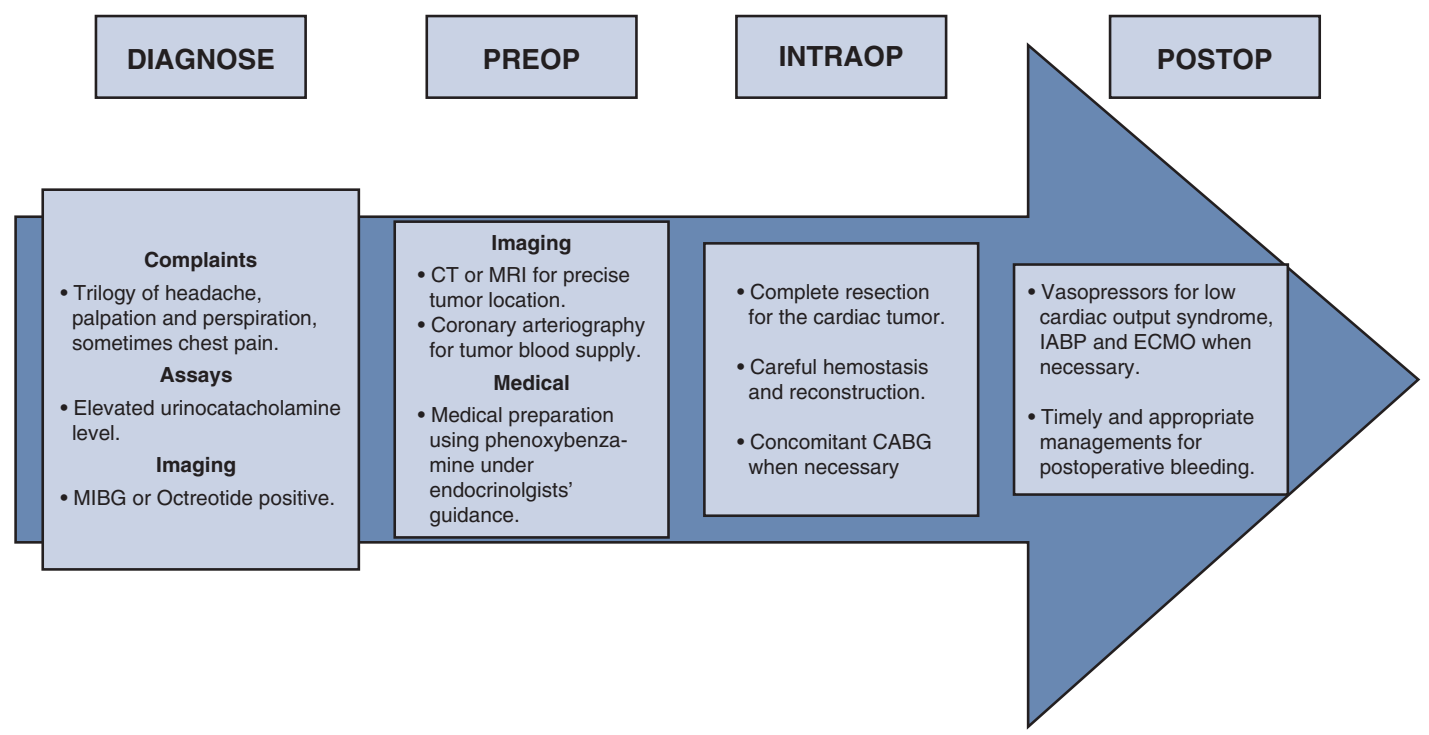

FIGURE 6. The process of diagnosis and treatment concluded from our 13 years of experience at Peking Union Medical College (PUMC). PREOP, Preoperative; INTRAOP, intraoperative; POSTOP, postoperative; $M I B G$, metaiodoben-zylguanidine scintigraphy; $C T$, computed tomography; $M R I$, magnetic resonance imaging; $C A B G$, coronary artery bypass grafting; $I A B P$, intra-aortic balloon pumping; $E C M O$, extracorporeal membrane oxygenator.

former studies of other institutions years ago. All these factors can reduce the credibility and affect the extrapolation of our conclusions.

\section{Conflict of Interest Statement}

Authors have nothing to disclose with regard to commercial support.

\section{References}

1. Gurrieri C, Butz JJ, Weingarten TN, Bancos I, Young WF Jr, Cassivi SD, et al. Resection of intrathoracic paraganglioma with and without cardiopulmonary bypass. Ann Thorac Surg. 2018;105:1160-7.

2. Martucci VL, Pacak K. Pheochromocytoma and paraganglioma: diagnosis, genetics, management, and treatment. Curr Probl Cancer. 2014:38:7-41.

3. Ramlawi B, David EA, Kim MP, Garcia-Morales LJ, Blackmon SH, Rice DC, et al. Contemporary surgical management of cardiac paragangliomas. Ann Thorac Surg. 2012;93:1972-6.

4. Liu X, Miao Q, Zhang H, Zhang C, Cao L, Ma G, et al. Primary cardiac pheochromocytoma involving both right and left atria. Ann Thorac Surg. 2013;95:337-40.

5. Zhang C, Ma G, Liu X, Zhang H, Deng H, Nowell J, et al. Primary cardiac pheochromocytoma with multiple endocrine neoplasia. J Cancer Res Clin Oncol. 2011;137:1289-91

6. Chen H, Sippel RS, O'Dorisio MS, Vinik AI, Lloyd RV, Pacak K, North American Neuroendocrine Tumor Society. The North American Neuroendocrine Tumor Society consensus guideline for the diagnosis and management of neuroendocrine tumors: pheochromocytoma, paraganglioma, and medullary thyroid cancer. Pancreas. 2010;39:775-83.

7. Wang JG, Han J, Jiang T, Li YJ. Cardiac paragangliomas. J Card Surg. 2015;30: 55-60.
8. Fishbein L, Merrill S, Fraker DL, Cohen DL, Nathanson KL. Inherited mutations in pheochromocytoma and paraganglioma: why all patients should be offered genetic testing. Ann Surg Oncol. 2013;20:1444-50.

9. Brown ML, Zayas GE, Abel MD, Young WF Jr, Schaff HV. Mediastinal paragangliomas: the mayo clinic experience. Ann Thorac Surg. 2008;86: 946-51.

10. Erickson D, Kudva YC, Ebersold MJ, Thompson GB, Grant CS, van Heerden JA, et al. Benign paragangliomas: clinical presentation and treatment outcomes in 236 patients. J Clin Endocrinol Metab. 2001;86:5210-6.

11. Jeevanandam V, Oz MC, Shapiro B, Barr ML, Marboe C, Rose EA. Surgical management of cardiac pheochromocytoma. Resection versus transplantation. Ann Surg. 1995;221:415-9.

12. Welander J, Soderkvist P, Gimm O. Genetics and clinical characteristics of hereditary pheochromocytomas and paragangliomas. Endocr Relat Cancer. 2011;18: R253-76.

13. Bravo EL, Tagle R. Pheochromocytoma: state-of-the-art and future prospects. Endocr Rev. 2003;24:539-53.

14. Ulchaker JC, Goldfarb DA, Bravo EL, Novick AC. Successful outcomes in pheochromocytoma surgery in the modern era. J Urol. 1999;161:764-7.

15. DeLellis RA, Lloyd RV, Heitz PU, Eng C. Pathology and Genetics of Tumours of the Endocrine Organs. WHO Classification of Tumours. Lyon, France: IARC Press; 2004.

16. Hamidi O, Young WF Jr, Iniguez-Ariza NM, Kittah NE, Gruber L, Bancos C, et al. Malignant pheochromocytoma and paraganglioma: 272 patients over 55 years. J Clin Endocrinol Metab. 2017;102:3296-305.

17. Stehlik J, Edwards LB, Kucheryavaya AY, Benden C, Christie JD, Dobbels F, et al. The Registry of the International Society for Heart and Lung Transplantation: Twenty-eighth Adult Heart Transplant Report-2011. J Heart Lung Transplant. 2011;30:1078-94.

Key Words: cardiac paraganglioma, cardiac surgery 